\title{
Outcomes of renal transplant in elderly
}

\author{
Anvita Anne, Varun Kumar Bandi
}

Department of Nephrology, Dr. Pinnamaneni Siddhartha Institute of Medical Sciences \& Research Foundation, Chinoutpalli, India

Background: The number of people requiring renal replacement therapy is on a rise, and the elderly population is among the rapidly growing groups, especially in the western world.

Methods: All renal transplants done at our center between 2004 to 2018 were reviewed. Transplant recipients with age $>60$ years were included for analysis and follow-up data was collected. Patients with incomplete data were excluded from analysis.

Results: A total of 22 patients were identified, of whom four were excluded due to incomplete data. The mean age was 63 years, with one among the 18 recipients being female. The $72.2 \%$ were between $60-64$ years of age, while $22.2 \%$ were between $65-69$ years of age, and one was $>70$ years of age. Live transplant was done in $44.4 \%$, with wife and son being most common donors ( $16.7 \%$ each), followed by one each from daughter and brother. The 1-, 3-, and 7-year patient survival were $83.3 \%, 66.7 \%$, and $25 \%$ respectively, while 1-, 3-, and 7-year graft survival were $88.9 \%, 60 \%$, and $25 \%$, respectively. Death with a functioning graft was present in $27.8 \%$ of patients. The patient and graft survival at 3 years were better with live donors compared to deceased donors. The major causes for mortality were sepsis $(50 \%)$ followed by cardiovascular death $(31.3 \%)$, with respiratory infection being the most common cause of sepsis related death (25\%). The cost analysis of patients receiving renal replacement therapy showed high initial costs with renal transplant, which reduced over long term and equals that of hemodialysis by about 26 months post-transplant.

Conclusions: With ageing general population, physicians are expected to make increasing number of decisions regarding transplantation candidacy in elderly patients. Elderly patients have good survival with kidney transplantation, and it also an economically more viable option.

Corresponding author: Anvita Anne

E-mail: aanvita1996@gmail.com

(C) The Korean Society for Transplantation

This is an Open Access article distributed under the terms of the Creative Commons Attribution Non-Commercial License (http://creativecommons.org/licenses/by-nc/4.0/) which permits unrestricted non-commercial use, distribution, and reproduction in any medium, provided the original work is properly cited. 